\title{
Characterizing NTU-bankruptcy rules using bargaining axioms
}

Citation for published version (APA):

Dietzenbacher, B., \& Peters, H. (2018). Characterizing NTU-bankruptcy rules using bargaining axioms. Maastricht University, Graduate School of Business and Economics. GSBE Research Memoranda No. 006 https://doi.org/10.26481/umagsb.2018006

Document status and date:

Published: 08/02/2018

DOI:

10.26481/umagsb.2018006

Document Version:

Publisher's PDF, also known as Version of record

\section{Please check the document version of this publication:}

- A submitted manuscript is the version of the article upon submission and before peer-review. There can be important differences between the submitted version and the official published version of record.

People interested in the research are advised to contact the author for the final version of the publication, or visit the DOI to the publisher's website.

- The final author version and the galley proof are versions of the publication after peer review.

- The final published version features the final layout of the paper including the volume, issue and page numbers.

Link to publication

\footnotetext{
General rights rights.

- You may freely distribute the URL identifying the publication in the public portal. please follow below link for the End User Agreement:

www.umlib.nl/taverne-license

Take down policy

If you believe that this document breaches copyright please contact us at:

repository@maastrichtuniversity.nl

providing details and we will investigate your claim.
}

Copyright and moral rights for the publications made accessible in the public portal are retained by the authors and/or other copyright owners and it is a condition of accessing publications that users recognise and abide by the legal requirements associated with these

- Users may download and print one copy of any publication from the public portal for the purpose of private study or research.

- You may not further distribute the material or use it for any profit-making activity or commercial gain

If the publication is distributed under the terms of Article $25 \mathrm{fa}$ of the Dutch Copyright Act, indicated by the "Taverne" license above, 


\section{Maastricht University}

Bas Dietzenbacher, Hans Peters

Characterizing NTU-

Bankruptcy Rules using

Bargaining Axioms

RM/18/006

\section{GSBE}

Maastricht University School of Business and Economics

Graduate School of Business and Economics

P.O Box 616

NL- 6200 MD Maastricht

The Netherlands 


\title{
Characterizing NTU-Bankruptcy Rules using Bargaining Axioms
}

\author{
Bas Dietzenbacher*† Hans Peters ${ }^{\ddagger}$
}

February 1, 2018

\begin{abstract}
This paper takes an axiomatic bargaining approach to bankruptcy problems with nontransferable utility by characterizing bankruptcy rules in terms of properties from bargaining theory. In particular, we derive new axiomatic characterizations of the proportional rule, the truncated proportional rule, and the constrained relative equal awards rule using properties which concern changes in the estate or the claims.
\end{abstract}

Keywords: NTU-bankruptcy problem, axiomatic analysis, bargaining theory JEL classification: C78, D74

\section{Introduction}

In a bankruptcy problem with nontransferable utility, claimants have incompatible claims on a deficient estate which corresponds to a set of utility allocations. Bankruptcy rules assign to any such bankruptcy problem a feasible utility allocation, i.e. an allocation for which the individual utility payoffs are bounded by the corresponding claims. On the one hand, bankruptcy problems with nontransferable utility generalize monetary bankruptcy problems (cf. O'Neill 1982). On the other hand, they can be considered as an alternative interpretation of bargaining problems with claims (cf. Chun and Thomson 1992).

Recently, Dietzenbacher, Estévez-Fernández, Borm, and Hendrickx (2016) and Dietzenbacher, Borm, and Estévez-Fernández (2017) took an axiomatic approach to bankruptcy problems with nontransferable utility by characterizing bankruptcy rules in terms of adequately generalized properties from bankruptcy theory. To explore the proportional rule, the truncated proportional rule, and the constrained relative equal awards rule, they introduced the relative symmetry axiom, which imposes a relatively equal treatment of relatively equal claimants, and the truncation invariance axiom, which imposes invariance under truncation of the claims by the estate.

Orshan, Valenciano, and Zarzuelo (2003), Estévez-Fernández, Borm, and Fiestras-Janeiro (2014) and Dietzenbacher (2018) took a game theoretic approach to bankruptcy problems with nontransferable utility by defining an appropriate coalitional bankruptcy game and focusing on the structure of the core. Besides, Dietzenbacher (2018) characterized the class of game theoretic bankruptcy rules by the truncation invariance property.

\footnotetext{
${ }^{*}$ E-mail: b.j.dietzenbacher@tilburguniversity.edu

${ }^{\dagger}$ CentER and Department of Econometrics and Operations Research, Tilburg University, P.O. Box 90153, 5000 LE Tilburg, The Netherlands

‡Department of Quantitative Economics, Maastricht University, P.O. Box 616, 6200 MD Maastricht, The Netherlands
} 
This paper takes an axiomatic bargaining approach to bankruptcy problems with nontransferable utility by characterizing bankruptcy rules in terms of properties from bargaining theory. Similar to Chun and Thomson (1992), we interpret the estate of a bankruptcy problem as the feasible set of a bargaining problem as introduced by Nash (1950) which is enriched by a claims vector. However, we adopt the standard assumption from bankruptcy theory that individual utility is normalized in such a way that allocating nothing corresponds to a utility level of zero. Therefore, it is convenient to consider the zero vector as a natural benchmark for allocations instead of an exogenous disagreement point as within bargaining problems. Although not addressed in this paper, this does still allow for the approach of Herrero (1997), which interprets the vector of minimal rights of a bankruptcy problem, the maximal individual payoffs within the estate when all other claimants are allocated their claims, as the corresponding endogenous disagreement point of a bargaining problem with claims.

We consider the role of the claims vector within bankruptcy problems as being 'dual' to the role of the disagreement point within bargaining problems. Where the disagreement point serves as a lower bound for rational payoff allocations within a bargaining problem, the claims vector serves as an upper bound for feasible payoff allocations within a bankruptcy problem. Following the classical axiomatic theory of bargaining, we formulate several properties which concern changes in the estate or the claims, where the latter ones are based on axioms concerning changes in the disagreement point, and study their implications. In particular, we translate several axioms from bargaining theory to the domain of bankruptcy problems with nontransferable utility, study their relations, and combine them with the standard axioms of relative symmetry and truncation invariance from bankruptcy theory to derive new axiomatic characterizations of the proportional rule, the truncated proportional rule, and the constrained relative equal awards rule.

This paper is organized in the following way. Section 2 provides an overview of notions for bankruptcy problems with nontransferable utility. In Section 3, we introduce and study the implications of axioms concerning changes in the estate. In Section 4 , we introduce and study the implications of axioms concerning changes in the claims. Section 5 concludes and formulates some suggestions for future research.

\section{Preliminaries}

Let $N$ be a nonempty and finite set of claimants. For any $x, y \in \mathbb{R}_{+}^{N}, x \leq y$ denotes $x_{i} \leq y_{i}$ for all $i \in N$, and $x<y$ denotes $x_{i}<y_{i}$ for all $i \in N$. For any set of payoff allocations $E \subseteq \mathbb{R}_{+}^{N}$

- the comprehensive hull is given by $\operatorname{comp}(E)=\left\{x \in \mathbb{R}_{+}^{N} \mid \exists_{y \in E}: y \geq x\right\}$;

- the weak upper contour set is given by $\operatorname{WUC}(E)=\left\{x \in \mathbb{R}_{+}^{N} \mid \neg \exists_{y \in E}: y>x\right\}$;

- the weak Pareto set is given by $\mathrm{WP}(E)=\left\{x \in E \mid \neg \exists_{y \in E}: y>x\right\}$;

- the strong Pareto set is given by $\operatorname{SP}(E)=\left\{x \in E \mid \neg \exists_{y \in E, y \neq x}: y \geq x\right\}$.

Note that $\operatorname{SP}(E) \subseteq \mathrm{WP}(E) \subseteq \mathrm{WUC}(E)$. A set of payoff allocations $E \subseteq \mathbb{R}_{+}^{N}$ is called comprehensive if $E=\operatorname{comp}(E)$, and nonleveled if $\operatorname{SP}(E)=\mathrm{WP}(E)$. 
A bankruptcy problem with nontransferable utility (cf. Orshan et al. 2003) is a triple $(N, E, c)$ in which $E \subseteq \mathbb{R}_{+}^{N}$ is a nonempty, closed, bounded, comprehensive, and nonleveled estate for which $E \neq\left\{0_{N}\right\}$, and $c \in \mathrm{WUC}(E)$ is a vector of claims. Let $\mathrm{BR}^{N}$ denote the class of all bankruptcy problems with claimant set $N$. For convenience, an NTU-bankruptcy problem is denoted by $(E, c) \in \mathrm{BR}^{N}$. Note that $0_{N} \in E$ and $\operatorname{WUC}(E)$ is closed for all $(E, c) \in$ $\mathrm{BR}^{N}$. Moreover, both $\left(E \cup E^{\prime}, c\right) \in \mathrm{BR}^{N}$ and $\left(E \cap E^{\prime}, c\right) \in \mathrm{BR}^{N}$ for all $(E, c),\left(E^{\prime}, c\right) \in \mathrm{BR}^{N}$.

Let $(E, c) \in \mathrm{BR}^{N}$. The set of positive claimants is given by

$$
N_{+}^{c}=\left\{i \in N \mid c_{i}>0\right\}
$$

The truncated estate $\hat{E}_{c} \subseteq \mathbb{R}_{+}^{N}$ is given by

$$
\hat{E}_{c}=\{x \in E \mid x \leq c\} .
$$

The vector of utopia values $u^{E} \in \mathbb{R}_{++}^{N}$ is given by

$$
u^{E}=\left(\max \left\{x_{i} \mid x \in E\right\}\right)_{i \in N} .
$$

The vector of truncated claims $\hat{c}^{E} \in \mathbb{R}_{+}^{N}$ is given by

$$
\hat{c}^{E}=\left(\min \left\{c_{i}, u_{i}^{E}\right\}\right)_{i \in N} .
$$

Note that $N_{+}^{c} \neq \emptyset, u^{\hat{E}_{c}}=\hat{c}^{E}$, and $\hat{E}_{c}=\hat{E}_{\hat{c}^{E}}$.

\section{Example 1}

Let $N=\{1,2\}$ and consider the bankruptcy problem $(E, c) \in \mathrm{BR}^{N}$ given by $E=\left\{x \in \mathbb{R}_{+}^{N} \mid\right.$ $\left.x_{1}^{2}+12 x_{2} \leq 36\right\}$ and $c=(3,4)$. Then $N_{+}^{c}=\{1,2\}, \hat{E}_{c}=\left\{x \in \mathbb{R}_{+}^{N} \mid x_{1}^{2}+12 x_{2} \leq 36, x_{1} \leq 3\right\}$, $u^{E}=(6,3)$, and $\hat{c}^{E}=(3,3)$.

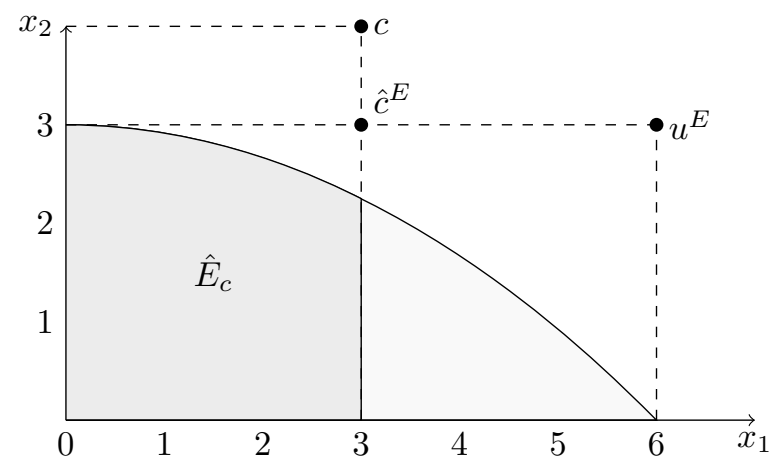

A bankruptcy rule $f: \mathrm{BR}^{N} \rightarrow \mathbb{R}_{+}^{N}$ assigns to any $(E, c) \in \mathrm{BR}^{N}$ a payoff allocation $f(E, c) \in \mathrm{WP}(E)$ for which $f(E, c) \leq c$. A bankruptcy rule $f: \mathrm{BR}^{N} \rightarrow \mathbb{R}_{+}^{N}$ satisfies

- relative symmetry if $\frac{f_{i}(E, c)}{u_{i}^{E}}=\frac{f_{j}(E, c)}{u_{j}^{E}}$ for all $(E, c) \in \mathrm{BR}^{N}$ and any $i, j \in N$ for which $\frac{c_{i}}{u_{i}^{E}}=\frac{c_{j}}{u_{j}^{E}}$

- truncation invariance if $f(E, c)=f\left(E, \hat{c}^{E}\right)$ for all $(E, c) \in \mathrm{BR}^{N}$.

The properties relative symmetry and truncation invariance are standard within bankruptcy theory. The use of utopia values is also standard within bargaining theory since the seminal work of Raiffa (1953) and Kalai and Smorodinsky (1975). 
The proportional rule Prop : $\mathrm{BR}^{N} \rightarrow \mathbb{R}_{+}^{N}$ (cf. Dietzenbacher et al. 2016) assigns to any $(E, c) \in \mathrm{BR}^{N}$ the payoff allocation

$$
\operatorname{Prop}(E, c)=\lambda^{E, c} c,
$$

where $\lambda^{E, c}=\max \{t \in(0,1] \mid t c \in E\}$. The proportional rule satisfies relative symmetry, but does not satisfy truncation invariance.

The truncated proportional rule TProp : $\mathrm{BR}^{N} \rightarrow \mathbb{R}_{+}^{N}$ (cf. Dietzenbacher et al. 2017) assigns to any $(E, c) \in \mathrm{BR}^{N}$ the payoff allocation

$$
\operatorname{TProp}(E, c)=\operatorname{Prop}\left(E, \hat{c}^{E}\right) .
$$

The truncated proportional rule satisfies both relative symmetry and truncation invariance.

The constrained relative equal awards rule CREA : $\mathrm{BR}^{N} \rightarrow \mathbb{R}_{+}^{N}$ (cf. Dietzenbacher et al. 2016) assigns to any $(E, c) \in \mathrm{BR}^{N}$ the payoff allocation

$$
\operatorname{CREA}(E, c)=\left(\min \left\{c_{i}, \alpha^{E, c} u_{i}^{E}\right\}\right)_{i \in N},
$$

where $\alpha^{E, c}=\max \left\{t \in(0,1] \mid\left(\min \left\{c_{i}, t u_{i}^{E}\right\}\right)_{i \in N} \in E\right\}$. The constrained relative equal awards rule satisfies both relative symmetry and truncation invariance.

\section{Example 2}

Let $N=\{1,2\}$ and consider the bankruptcy problem $(E, c) \in \mathrm{BR}^{N}$ given by $E=\{x \in$ $\left.\mathbb{R}_{+}^{N} \mid x_{1}^{2}+12 x_{2} \leq 36\right\}$ and $c=(3,4)$ as in Example 11. Then $\operatorname{Prop}(E, c)=\left(2,2 \frac{2}{3}\right)$

$\operatorname{TProp}(E, c)=(6 \sqrt{2}-6,6 \sqrt{2}-6)(*)$, and $\operatorname{CREA}(E, c)=\left(3,2 \frac{1}{4}\right)$

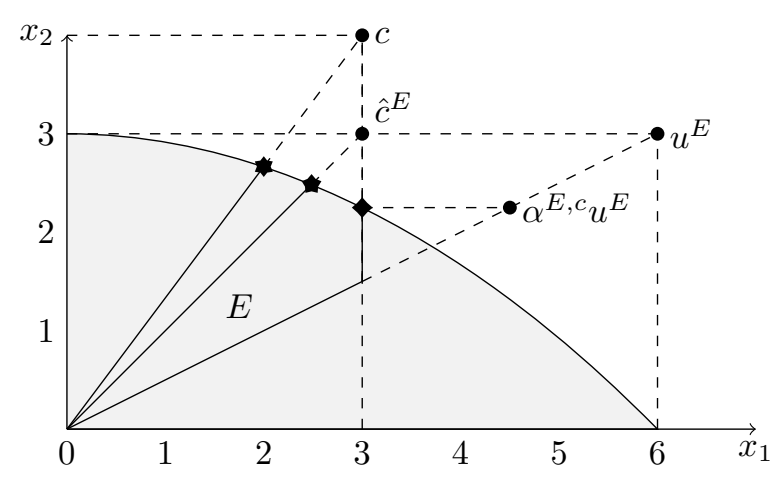

\section{Modifying the Estate}

In this section, we introduce and study the implications of axioms concerning changes in the estate. Starting from the well-known independence of irrelevant alternatives axiom introduced by Nash (1950), several axioms concerning changes in the feasible set of bargaining problems have been proposed in the literature. Kalai (1977) introduced a strong monotonicity axiom and the axiom of step-by-step negotiations, which were further studied by Roth (1979). Thomson and Myerson (1980) introduced the axioms domination and independence of undominating alternatives. Peters (2010) introduced the independence of nonindividually rational outcomes axiom to describe solutions for bargaining problems which only depend on the rational payoff allocations within the feasible set. 
As exploited by Roth (1977) for the independence of irrelevant alternatives axiom, in the formulation of these properties the disagreement point is required to be fixed. We translate these properties to the domain of bankruptcy problems with nontransferable utility in such a way that the vector of claims is required to be fixed. The translated axiom of Peters (2010) is used to describe bankruptcy rules which only depend on the feasible payoff allocations within the estate. Following Chun and Thomson (1992), this axiom is called independence of unclaimed alternatives.

Definition 3.1 (Estate Axioms)

A bankruptcy rule $f: \mathrm{BR}^{N} \rightarrow \mathbb{R}_{+}^{N}$ satisfies

- step-by-step negotiations if $f(E, c)=f\left(E^{\prime}, c\right)+f\left(\left(E-\left\{f\left(E^{\prime}, c\right)\right\}\right)_{+}, c-f\left(E^{\prime}, c\right)\right)$ for all $(E, c),\left(E^{\prime}, c\right) \in \mathrm{BR}^{N}$ for which $E^{\prime} \subseteq E$;

- estate monotonicity if $f(E, c) \geq f\left(E^{\prime}, c\right)$ for all $(E, c),\left(E^{\prime}, c\right) \in \mathrm{BR}^{N}$ for which $E^{\prime} \subseteq E$;

- domination if $f(E, c) \leq f\left(E^{\prime}, c\right)$ or $f(E, c) \geq f\left(E^{\prime}, c\right)$ for all $(E, c),\left(E^{\prime}, c\right) \in \mathrm{BR}^{N}$;

- independence of irrelevant alternatives if $f(E, c)=f\left(E^{\prime}, c\right)$ for all $(E, c),\left(E^{\prime}, c\right) \in \mathrm{BR}^{N}$ for which $E^{\prime} \subseteq E$ and $f(E, c) \in \mathrm{WP}\left(E^{\prime}\right)$;

- independence of undominating alternatives if $f(E, c)=f\left(E^{\prime}, c\right)$ for all $(E, c),\left(E^{\prime}, c\right) \in$ $\mathrm{BR}^{N}$ for which $E^{\prime} \subseteq E$ and $f\left(E^{\prime}, c\right) \in \mathrm{WP}(E)$;

- independence of unclaimed alternatives if $f(E, c)=f\left(E^{\prime}, c\right)$ for all $(E, c),\left(E^{\prime}, c\right) \in \mathrm{BR}^{N}$ for which $\hat{E}_{c}=\hat{E}_{c}^{\prime}$.

Note that the proportional rule satisfies all these properties. The following lemma studies the relations between the estate axioms. Some of these relations bear some similarities with the results of Thomson and Myerson (1980). The proof is provided in the appendix.

\section{Lemma 3.1}

Let $f: \mathrm{BR}^{N} \rightarrow \mathbb{R}_{+}^{N}$ be a bankruptcy rule.

(i) If $f$ satisfies step-by-step negotiations, then $f$ satisfies estate monotonicity.

(ii) If $f$ satisfies estate monotonicity, then $f$ satisfies domination.

(iii) If $f$ satisfies domination, then $f$ satisfies estate monotonicity.

(iv) If $f$ satisfies estate monotonicity, then $f$ satisfies independence of irrelevant alternatives.

(v) If $f$ satisfies estate monotonicity, then $f$ satisfies independence of undominating alternatives.

(vi) If $f$ satisfies independence of irrelevant alternatives, then $f$ satisfies independence of unclaimed alternatives.

(vii) If $f$ satisfies independence of undominating alternatives, then $f$ satisfies independence of unclaimed alternatives.

${ }^{1}$ Here, $\left(E-\left\{f\left(E^{\prime}, c\right)\right\}\right)_{+}=\left\{x \in \mathbb{R}_{+}^{N} \mid x+f\left(E^{\prime}, c\right) \in E\right\}$. 
Lemma 3.1 can be summarized by the following diagram.

$$
\text { step-by-step negotiations }
$$

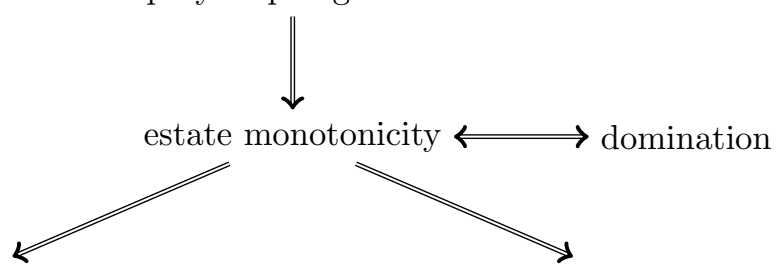

independence of irrelevant alternatives independence of undominating alternatives

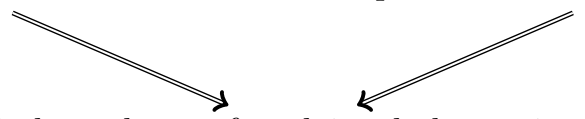

independence of unclaimed alternatives

The bankruptcy rule $f: \mathrm{BR}^{N} \rightarrow \mathbb{R}_{+}^{N}$ which assigns to any $(E, c) \in \mathrm{BR}^{N}$ the payoff allocation

$$
f(E, c)= \begin{cases}\left(\hat{c}_{i_{+}}^{E}, \max \left\{x \mid\left(\hat{c}_{i_{+}}^{E}, x\right) \in E\right\}\right) & \text { if } N=\{1,2\} \\ \operatorname{Prop}(E, c) & \text { otherwise }\end{cases}
$$

where $i_{+}=\max \left\{\operatorname{argmax}_{i \in N}\left\{\hat{c}_{i}^{E}\right\}\right\}$, satisfies independence of irrelevant alternatives, but does not satisfy independence of undominating alternatives.

The bankruptcy rule $f: \mathrm{BR}^{N} \rightarrow \mathbb{R}_{+}^{N}$ which assigns to any $(E, c) \in \mathrm{BR}^{N}$ the payoff allocation

$$
f(E, c)= \begin{cases}\left(\hat{c}_{i_{-}}^{E}, \max \left\{x \mid\left(\hat{c}_{i_{-}}^{E}, x\right) \in E\right\}\right) & \text { if } N=\{1,2\} \\ \operatorname{Prop}(E, c) & \text { otherwise }\end{cases}
$$

where $i_{-}=\min \left\{\operatorname{argmin}_{i \in N}\left\{\hat{c}_{i}^{E}\right\}\right\}$, satisfies independence of undominating alternatives, but does not satisfy independence of irrelevant alternatives.

This means that the properties independence of irrelevant alternatives and independence of undominating alternatives are independent. However, if relative symmetry is required in addition, then the two properties become equivalent and are only satisfied by the proportional rule.

\section{Theorem 3.2}

The proportional rule is the unique bankruptcy rule satisfying relative symmetry and independence of irrelevant alternatives.

Proof. The proportional rule satisfies relative symmetry. By Lemma 3.1 and Lemma A.1 or by direct inspection, the proportional rule satisfies independence of irrelevant alternatives. Let $f: \mathrm{BR}^{N} \rightarrow \mathbb{R}_{+}^{N}$ be a bankruptcy rule satisfying relative symmetry and independence of irrelevant alternatives. Let $(E, c) \in \mathrm{BR}^{N}$. Denote

$$
t=\max _{i \in N_{+}^{c}}\left\{\frac{u_{i}^{E}}{c_{i}}\right\} \text { and } \varepsilon=\min _{i \in N_{+}^{c}}\left\{\operatorname{Prop}_{i}(E, c)\right\} .
$$

Define

$$
E^{\prime}=\bigcup_{i \in N_{+}^{c}} \operatorname{comp}\left(\operatorname{conv}\left(\left\{\left(t c_{i}, 0_{N \backslash\{i\}}\right)\right\} \cup\left\{\left(\varepsilon, 0_{N \backslash\{j\}}\right) \mid j \in N\right\}\right)\right) \cup E .
$$

\footnotetext{
${ }^{2}$ Throughout this paper, we refer to the appendix for the derivations of properties satisfied by specific bankruptcy rules.
} 


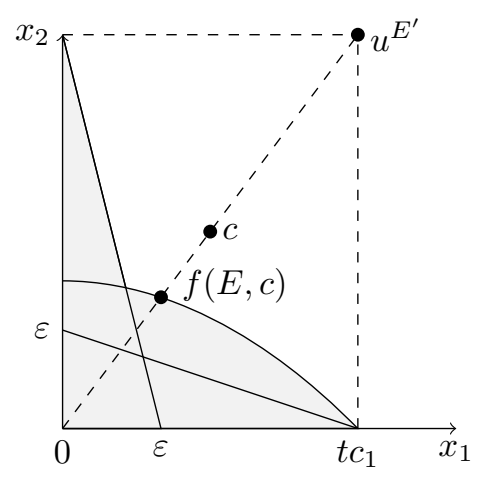

Then $\left(E^{\prime}, c\right) \in \mathrm{BR}^{N}$ and $E \subseteq E^{\prime}$. Moreover, $u_{N_{+}^{c}}^{E^{\prime}}=t c_{N_{+}^{c}}$ and $\lambda^{E^{\prime}, c}=\lambda^{E, c}$. We have $c_{i} u_{j}^{E^{\prime}}=t c_{i} c_{j}=c_{j} u_{i}^{E^{\prime}}$ for all $i, j \in N_{+}^{c}$. Since $f$ satisfies relative symmetry, this means that $f\left(E^{\prime}, c\right)=\lambda^{E^{\prime}, c} c=\lambda^{E, c} c=\operatorname{Prop}(E, c)$. Since $f$ satisfies independence of irrelevant alternatives, this implies that $f(E, c)=f\left(E^{\prime}, c\right)=\operatorname{Prop}(E, c)$.

\section{Theorem 3.3}

The proportional rule is the unique bankruptcy rule satisfying relative symmetry and independence of undominating alternatives.

Proof. The proportional rule satisfies relative symmetry. By Lemma 3.1 and Lemma A.1 or by direct inspection, the proportional rule satisfies independence of undominating alternatives. Let $f: \mathrm{BR}^{N} \rightarrow \mathbb{R}_{+}^{N}$ be a bankruptcy rule satisfying relative symmetry and independence of undominating alternatives. Let $(E, c) \in \mathrm{BR}^{N}$. Denote

$$
t=\min _{i \in N_{+}^{c}}\left\{\frac{u_{i}^{E}}{c_{i}}\right\} \text { and } \varepsilon= \begin{cases}\min _{i \in N \backslash N_{+}^{c}}\left\{u_{i}^{E}\right\} & \text { if } N \backslash N_{+}^{c} \neq \emptyset ; \\ 0 & \text { if } N \backslash N_{+}^{c}=\emptyset .\end{cases}
$$

Define

$E^{\prime}=\operatorname{comp}\left(\operatorname{conv}\left(\{\operatorname{Prop}(E, c)\} \cup\left\{\left(t c_{i}, 0_{N \backslash\{i\}}\right) \mid i \in N_{+}^{c}\right\} \cup\left\{\left(\varepsilon, 0_{N \backslash\{i\}}\right) \mid i \in N \backslash N_{+}^{c}\right\}\right)\right) \cap E$.

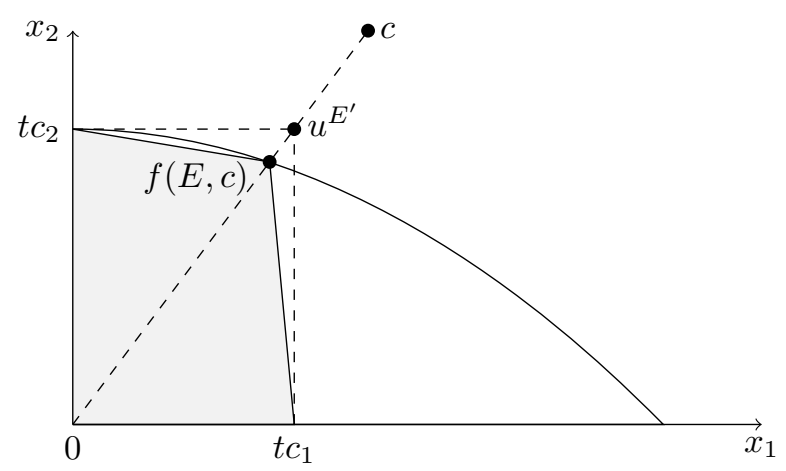

Then $\left(E^{\prime}, c\right) \in \mathrm{BR}^{N}$ and $E^{\prime} \subseteq E$. Moreover, $u_{N_{+}^{c}}^{E^{\prime}}=t c_{N_{+}^{c}}$ and $\lambda^{E^{\prime}, c}=\lambda^{E, c}$. We have $c_{i} u_{j}^{E^{\prime}}=t c_{i} c_{j}=c_{j} u_{i}^{E^{\prime}}$ for all $i, j \in N_{+}^{c}$. Since $f$ satisfies relative symmetry, this means that $f\left(E^{\prime}, c\right)=\lambda^{E^{\prime}, c} c=\lambda^{E, c} c=\operatorname{Prop}(E, c)$. Since $f$ satisfies independence of undominating alternatives, this implies that $f(E, c)=f\left(E^{\prime}, c\right)=\operatorname{Prop}(E, c)$. 
To show that relative symmetry is independent of any estate axiom, we introduce the constrained equal awards rule. The constrained equal awards rule $\mathrm{CEA}: \mathrm{BR}^{N} \rightarrow \mathbb{R}_{+}^{N}$ assigns to any $(E, c) \in \mathrm{BR}^{N}$ the payoff allocation

$$
\operatorname{CEA}(E, c)=\left(\min \left\{c_{i}, a\right\}\right)_{i \in N},
$$

where $a \in \mathbb{R}_{+}$is such that $\operatorname{CEA}(E, c) \in \mathrm{WP}(E)$.

Where the constrained relative equal awards rule aims to allocate payoffs relatively equal among the claimants, the constrained equal awards rule aims to allocate payoffs absolutely equal among the claimants. The constrained relative equal awards rule satisfies relative symmetry, but does not satisfy independence of unclaimed alternatives. The constrained equal awards rule satisfies step-by-step negotiations, but does not satisfy relative symmetry.

\begin{tabular}{l||c||c|c} 
& Prop & CREA & CEA \\
\hline relative symmetry & $\checkmark$ & $\checkmark$ & \\
\hline step-by-step negotiations $--\bar{y}_{-}$ & $\checkmark$ & & $\checkmark$ \\
estate monotonicity & $\checkmark$ & & $\checkmark$ \\
domination & $\checkmark$ & & $\checkmark$ \\
independence of irrelevant alternatives & $\checkmark$ & & $\checkmark$ \\
independence of undominating alternatives & $\checkmark$ & & $\checkmark$ \\
independence of unclaimed alternatives & $\checkmark$ & & $\checkmark$
\end{tabular}

This means that relative symmetry is independent of any estate axiom. This implies that the properties in an axiomatic characterization of the proportional rule remain independent if independence of irrelevant alternatives in Theorem 3.2 or independence of undominating alternatives in Theorem 3.3 is strengthened to domination, estate monotonicity, or step-bystep negotiations.

The proportional rule is not the unique bankruptcy rule satisfying relative symmetry and independence of unclaimed alternatives, since the truncated proportional rule also satisfies these two properties. Nevertheless, we can formulate the following lemma.

\section{Lemma 3.4}

Let $f: \mathrm{BR}^{N} \rightarrow \mathbb{R}_{+}^{N}$ be a bankruptcy rule. If $f$ satisfies relative symmetry and independence of unclaimed alternatives, then $f(E, c)=\operatorname{Prop}(E, c)$ for all $(E, c) \in \mathrm{BR}^{N}$ for which $c<u^{E}$.

Proof. Assume that $f$ satisfies relative symmetry and independence of unclaimed alternatives. Let $(E, c) \in \mathrm{BR}^{N}$ be such that $c<u^{E}$. Then $\left|N_{+}^{c}\right| \geq 2$. Let

$$
t=\max _{i \in N_{+}^{c}}\left\{\frac{u_{i}^{E}}{c_{i}}\right\} \text { and } \varepsilon=\min _{i, j \in N_{+}^{c}}\left\{x_{i} \mid\left(x_{i}, c_{j}, 0_{N \backslash\{i, j\}}\right) \in \operatorname{WP}(E)\right\} .
$$

Define

$$
E^{\prime}=\bigcup_{i \in N_{+}^{c}} \operatorname{comp}\left(\operatorname{conv}\left(\left\{\left(t c_{i}, 0_{N \backslash\{i\}}\right)\right\} \cup\left\{\left(\varepsilon, 0_{N \backslash\{j\}}\right) \mid j \in N\right\}\right)\right) \cup E .
$$




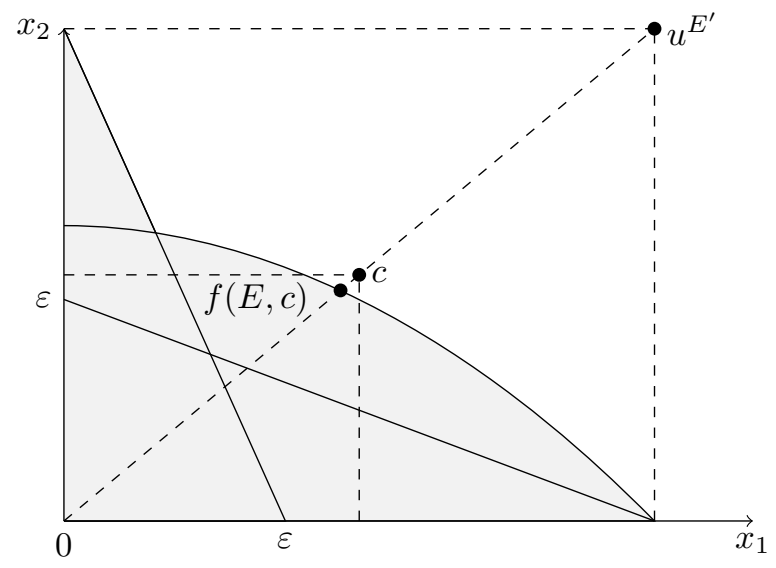

Then $\left(E^{\prime}, c\right) \in \mathrm{BR}^{N}$ and $\hat{E}_{c}=\hat{E}_{c}^{\prime}$. Moreover, $u_{N_{+}^{c}}^{E^{\prime}}=t c_{N_{+}^{c}}$ and $\lambda^{E^{\prime}, c}=\lambda^{E, c}$. We have $c_{i} u_{j}^{E^{\prime}}=t c_{i} c_{j}=c_{j} u_{i}^{E^{\prime}}$ for all $i, j \in N_{+}^{c}$. Since $f$ satisfies relative symmetry, this means that $f\left(E^{\prime}, c\right)=\lambda^{E^{\prime}, c} c=\lambda^{E, c} c=\operatorname{Prop}(E, c)$. Since $f$ satisfies independence of unclaimed alternatives, this implies that $f(E, c)=f\left(E^{\prime}, c\right)=\operatorname{Prop}(E, c)$.

If we combine independence of unclaimed alternatives with the standard bankruptcy axioms relative symmetry and truncation invariance, and the weak technical requirement claims continuity, we derive an axiomatic characterization of the truncated proportional rule by using Lemma 3.4 .

Definition 3.2 (Claims Continuity)

A bankruptcy rule $f: \mathrm{BR}^{N} \rightarrow \mathbb{R}_{+}^{N}$ satisfies claims continuity if $f(E, c)$ is continuous in $c$ for all $(E, c) \in \mathrm{BR}^{N}$.

\section{Theorem 3.5}

The truncated proportional rule is the unique bankruptcy rule satisfying relative symmetry, truncation invariance, independence of unclaimed alternatives, and claims continuity.

Proof. The truncated proportional rule satisfies relative symmetry and truncation invariance. By Lemma A.2 and Lemma A.3, the truncated proportional rule satisfies independence of unclaimed alternatives and claims continuity. Let $f: \mathrm{BR}^{N} \rightarrow \mathbb{R}_{+}^{N}$ be a bankruptcy rule satisfying relative symmetry, truncation invariance, independence of unclaimed alternatives, and claims continuity. Let $(E, c) \in \mathrm{BR}^{N}$. If $\left|N_{+}^{c}\right|=1$, then $f(E, c)=\left(u_{N_{+}^{c}}^{E}, 0_{N \backslash N_{+}^{c}}\right)=$ $\operatorname{TProp}(E, c)$. Suppose that $\left|N_{+}^{c}\right| \geq 2$. Let $\left\{x_{k}\right\}_{k \in \mathbb{N}}$ be a sequence in $\operatorname{WUC}(E)$ defined by $x_{k}=\frac{1}{k} \operatorname{Prop}\left(E, \hat{c}^{E}\right)+\left(1-\frac{1}{k}\right) \hat{c}^{E}$ for all $k \in \mathbb{N}$. Then $x_{k}<u^{E}$ for all $k \in \mathbb{N}$ and $\lim _{k \rightarrow \infty} x_{k}=$ $\hat{c}^{E}$. Since $f$ satisfies relative symmetry and independence of unclaimed alternatives, Lemma 3.4 implies that $f\left(E, x_{k}\right)=\operatorname{Prop}\left(E, x_{k}\right)=\operatorname{Prop}\left(E, \hat{c}^{E}\right)=\operatorname{TProp}(E, c)$ for all $k \in \mathbb{N}$. Since $f$ satisfies claims continuity, this means that $f\left(E, \hat{c}^{E}\right)=\lim _{k \rightarrow \infty} f\left(E, x_{k}\right)=\operatorname{TProp}(E, c)$. Since $f$ satisfies truncation invariance, this implies that $f(E, c)=f\left(E, \hat{c}^{E}\right)=\operatorname{TProp}(E, c)$. 
To show that the properties in Theorem 3.5 are independent, we introduce the restricted truncated proportional rule. The restricted truncated proportional rule RTProp : $\mathrm{BR}^{N} \rightarrow$ $\mathbb{R}_{+}^{N}$ assigns to any $(E, c) \in \mathrm{BR}^{N}$ the payoff allocation

$$
\operatorname{RTProp}(E, c)= \begin{cases}\operatorname{Prop}(E, c) & \text { if } c<u^{E} ; \\ \left(t u_{S}^{E}, 0_{N \backslash S}\right) & \text { otherwise }\end{cases}
$$

where $S=\left\{i \in N \mid c_{i} \geq u_{i}^{E}\right\}$ and $t \in(0,1]$ is $\operatorname{such}$ that $\operatorname{RTProp}(E, c) \in \operatorname{WP}(E)$.

The restricted truncated proportional rule satisfies relative symmetry, truncation invariance, and independence of unclaimed alternatives, but does not satisfy claims continuity. The constrained relative equal awards rule satisfies relative symmetry, truncation invariance, and claims continuity, but does not satisfy independence of unclaimed alternatives. The proportional rule satisfies relative symmetry, independence of unclaimed alternatives, and claims continuity, but does not satisfy truncation invariance. The constrained equal awards rule satisfies truncation invariance, independence of unclaimed alternatives, and claims continuity, but does not satisfy relative symmetry.

\begin{tabular}{l||c||c|c|c|c} 
& TProp & RTProp & CREA & Prop & CEA \\
\hline relative symmetry & $\checkmark$ & $\checkmark$ & $\checkmark$ & $\checkmark$ & \\
truncation invariance & $\checkmark$ & $\checkmark$ & $\checkmark$ & & $\checkmark$ \\
independence of unclaimed alternatives & $\checkmark$ & $\checkmark$ & & $\checkmark$ & $\checkmark$ \\
claims continuity & $\checkmark$ & & $\checkmark$ & $\checkmark$ & $\checkmark$
\end{tabular}

This means that the properties in Theorem 3.5 are independent.

\section{Shifting the Claims}

In this section, we introduce and study the implications of axioms concerning changes in the claims. Several axioms concerning changes in the disagreement point of bargaining problems have been proposed in the literature. We translate these properties to the domain of bankruptcy problems with nontransferable utility in such a way that they concern similar changes in the vector of claims while the estate is required to be fixed.

Livne (1988) and Chun and Thomson (1990) use a convexity axiom which imposes that convex combinations of disagreement points with equal outcomes lead to the same outcome. Peters and Van Damme (1991) and Peters (2010) use related axioms which impose that convex or linear combinations of a disagreement point and its corresponding outcome lead to the same outcome. We translate these properties, introduce an even stronger linearity axiom, and study their relations.

Definition 4.1 (Claims Axioms)

A bankruptcy rule $f: \mathrm{BR}^{N} \rightarrow \mathbb{R}_{+}^{N}$ satisfies

- claims linearity if $f(E, c)=f\left(E, \theta c+(1-\theta) c^{\prime}\right)$ for all $(E, c),\left(E, c^{\prime}\right) \in \mathrm{BR}^{N}$ for which $f(E, c)=f\left(E, c^{\prime}\right)$ and any $\theta \in \mathbb{R}$ for which $\left(E, \theta c+(1-\theta) c^{\prime}\right) \in \mathrm{BR}^{N}$;

- weak claims linearity if $f(E, c)=f(E, \theta c+(1-\theta) f(E, c))$ for all $(E, c) \in \mathrm{BR}^{N}$ and any $\theta \in \mathbb{R}_{+}$;

- claims convexity if $f(E, c)=f\left(E, \theta c+(1-\theta) c^{\prime}\right)$ for all $(E, c),\left(E, c^{\prime}\right) \in \mathrm{BR}^{N}$ for which $f(E, c)=f\left(E, c^{\prime}\right)$ and any $\theta \in[0,1]$;

- weak claims convexity if $f(E, c)=f(E, \theta c+(1-\theta) f(E, c))$ for all $(E, c) \in \mathrm{BR}^{N}$ and any $\theta \in[0,1]$. 
Note that the proportional rule satisfies all these properties. The following lemma presents the relations between the claims axioms.

\section{Lemma 4.1}

Let $f: \mathrm{BR}^{N} \rightarrow \mathbb{R}_{+}^{N}$ be a bankruptcy rule.

(i) If $f$ satisfies claims linearity, then $f$ satisfies weak claims linearity.

(ii) If $f$ satisfies claims linearity, then $f$ satisfies claims convexity.

(iii) If $f$ satisfies weak claims linearity, then $f$ satisfies weak claims convexity.

(iv) If $f$ satisfies claims convexity, then $f$ satisfies weak claims convexity.

Lemma 4.1 can be summarized by the following diagram.

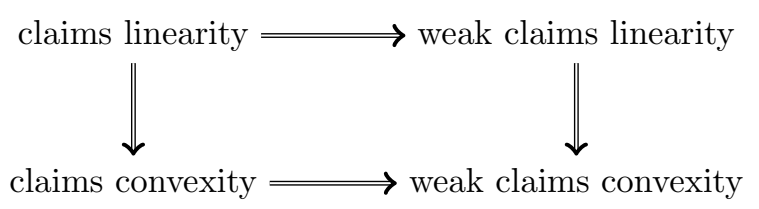

The bankruptcy rule $f: \mathrm{BR}^{N} \rightarrow \mathbb{R}_{+}^{N}$ which assigns to any $(E, c) \in \mathrm{BR}^{N}$ the payoff allocation

$$
f(E, c)= \begin{cases}\left(\hat{c}_{1}^{E}, \min \left\{c_{2}, t u_{2}^{E}\right\}, \min \left\{c_{3}, t u_{3}^{E}\right\}\right) & \text { if } N=\{1,2,3\} \text { and } c_{2} u_{3}^{E}=c_{3} u_{2}^{E} ; \\ \operatorname{CREA}(E, c) & \text { otherwise, }\end{cases}
$$

where $t \in[0,1]$ is such that $f(E, c) \in \mathrm{WP}(E)$, satisfies weak claims linearity, but does not satisfy claims convexity.

The restricted constrained relative equal awards rule $\mathrm{RCREA}: \mathrm{BR}^{N} \rightarrow \mathbb{R}_{+}^{N}$, which assigns to any $(E, c) \in \mathrm{BR}^{N}$ the payoff allocation

$$
\operatorname{RCREA}(E, c)= \begin{cases}\operatorname{CREA}(E, c) & \text { if } c<u^{E} \text { or } c \geq \lambda^{E, u^{E}} u^{E} \\ \left(t u_{S}^{E}, 0_{N \backslash S}\right) & \text { otherwise, }\end{cases}
$$

where $S=\left\{i \in N \mid c_{i} \geq u_{i}^{E}\right\}$ and $t \in(0,1]$ is such that $\operatorname{RCREA}(E, c) \in \mathrm{WP}(E)$, satisfies claims convexity, but does not satisfy weak claims linearity.

This means that the properties weak claims linearity and claims convexity are independent. If we combine these properties with the standard bankruptcy axioms relative symmetry and truncation invariance, the constrained relative equal awards rule is the only bankruptcy rule satisfying relative symmetry, truncation invariance, and weak claims linearity.

\section{Theorem 4.2}

The constrained relative equal awards rule is the unique bankruptcy rule satisfying relative symmetry, truncation invariance, and weak claims linearity.

Proof. The constrained relative equal awards rule satisfies relative symmetry and truncation invariance. By Lemma A.4, the constrained relative equal awards rule satisfies weak claims linearity. Let $f: \mathrm{BR}^{N} \rightarrow \mathbb{R}_{+}^{N}$ be a bankruptcy rule satisfying relative symmetry, truncation invariance, and weak claims linearity. Let $(E, c) \in \mathrm{BR}^{N}$. If $c \in E$, then $f(E, c)=c=$ $\operatorname{CREA}(E, c)$. Suppose that $c \notin E$ and denote $S=\left\{i \in N \mid f_{i}(E, c)<c_{i}\right\}$. Then $S \neq \emptyset$. 
Let $x \in \mathbb{R}_{+}^{N}$ with $x=\theta c+(1-\theta) f(E, c)$ for some $\theta \in \mathbb{R}_{+}$be such that $x_{S} \geq u_{S}^{E}$. Then $\hat{x}_{S}^{E}=\left(\min \left\{x_{i}, u_{i}^{E}\right\}\right)_{i \in S}=u_{S}^{E}$ and $\hat{x}_{i}^{E} u_{j}^{E}=u_{i}^{E} u_{j}^{E}=\hat{x}_{j}^{E} u_{i}^{E}$ for all $i, j \in S$. Since $f$ satisfies relative symmetry, this means that $f_{S}\left(E, \hat{x}^{E}\right)=t u_{S}^{E}$ for some $t \in[0,1]$. Since $f$ satisfies truncation invariance, this implies that $f_{S}(E, x)=f_{S}\left(E, \hat{x}^{E}\right)=t u_{S}^{E}$. Since $f$ satisfies weak claims linearity, $f_{S}(E, c)=f_{S}(E, x)=t u_{S}^{E}$. Then $f_{S}(E, c) \leq \alpha^{E, c} u_{S}^{E}$, since otherwise $f(E, c) \geq \operatorname{CREA}(E, c)$ and $f(E, c) \neq \operatorname{CREA}(E, c)$, which contradicts that $E$ is nonleveled.

Suppose that there exists an $i \in N \backslash S$ such that $f_{i}(E, c)>\alpha^{E, c} u_{i}^{E}$. Then $f_{j}(E, c) u_{i}^{E} \leq$ $\alpha^{E, c} u_{j}^{E} u_{i}^{E}<f_{i}(E, c) u_{j}^{E}$ for all $j \in S$. Let $y \in \mathbb{R}_{+}^{N}$ be such that $y=\theta c+(1-\theta) f(E, c)$ for some $\theta \in \mathbb{R}_{++}$and $y_{j} u_{i}^{E}=f_{i}(E, c) u_{j}^{E}$ for some $j \in S$. Then $y_{i} u_{j}^{E}=f_{i}(E, c) u_{j}^{E}=y_{j} u_{i}^{E}$. Since $f$ satisfies relative symmetry, this means that $f_{i}(E, y) u_{j}^{E}=f_{j}(E, y) u_{i}^{E}$. Since $f$ satisfies weak claims linearity, this implies that $f_{i}(E, c) u_{j}^{E}=f_{j}(E, c) u_{i}^{E}$. This is a contradiction. Hence, $f_{i}(E, c) \leq \min \left\{c_{i}, \alpha^{E, c} u_{i}^{E}\right\}=\operatorname{CREA}_{i}(E, c)$ for all $i \in N$. Since $E$ is nonleveled, this implies that $f(E, c)=\operatorname{CREA}(E, c)$.

The truncated proportional rule satisfies relative symmetry and truncation invariance, but does not satisfy weak claims linearity. The proportional rule satisfies relative symmetry and weak claims linearity, but does not satisfy truncation invariance. The constrained equal awards rule satisfies truncation invariance and weak claims linearity, but does not satisfy relative symmetry.

\begin{tabular}{l||c||c|c|c} 
& CREA & TProp & Prop & CEA \\
\hline relative symmetry & $\checkmark$ & $\checkmark$ & $\checkmark$ & \\
truncation invariance & $\checkmark$ & $\checkmark$ & & $\checkmark$ \\
weak claims linearity & $\checkmark$ & & $\checkmark$ & $\checkmark$
\end{tabular}

This means that the properties in Theorem 4.2 are independent. The constrained relative equal awards rule is not the unique bankruptcy rule satisfying relative symmetry, truncation invariance, and claims convexity, since the restricted constrained relative equal awards rule also satisfies these three properties.

The axioms concerning changes in the claims can also be combined with the axioms concerning changes in the estate. The proportional rule is not the unique bankruptcy rule satisfying relative symmetry and independence of unclaimed alternatives, since the truncated proportional rule also satisfies these two properties. However, if weak claims linearity is required in addition, then these properties are only satisfied by the proportional rule.

\section{Theorem 4.3}

The proportional rule is the unique bankruptcy rule satisfying relative symmetry, independence of unclaimed alternatives, and weak claims linearity.

Proof. The proportional rule satisfies relative symmetry. By Lemma 3.1, Lemma 4.1. Lemma A.1 and Lemma A.5, the proportional rule satisfies independence of unclaimed alternatives and weak claims linearity. Let $f: \mathrm{BR}^{N} \rightarrow \mathbb{R}_{+}^{N}$ be a bankruptcy rule satisfying relative symmetry, independence of unclaimed alternatives, and weak claims linearity. Let $(E, c) \in$ $\mathrm{BR}^{N}$. If $\left|N_{+}^{c}\right|=1$, then $f(E, c)=\left(u_{N_{+}^{c}}^{E}, 0_{N \backslash N_{+}^{c}}\right)=\operatorname{Prop}(E, c)$. Suppose that $\left|N_{+}^{c}\right| \geq 2$. Let $x \in \mathbb{R}_{+}^{N}$ with $x=\theta c+(1-\theta) \operatorname{Prop}(E, c)$ for some $\theta \in(0,1]$ be such that $x<u^{E}$. Since $f$ satisfies relative symmetry and independence of unclaimed alternatives, Lemma 3.4 implies that $f(E, x)=\operatorname{Prop}(E, x)=\operatorname{Prop}(E, c)$. Since $f$ satisfies weak claims linearity, this implies that $f(E, c)=f\left(E, \frac{1}{\theta} x+\left(1-\frac{1}{\theta}\right) f(E, x)\right)=f(E, x)=\operatorname{Prop}(E, c)$. 
To show that relative symmetry and independence of unclaimed alternatives are independent of any claims axiom, we introduce two classes of bankruptcy rules. First, let $\Psi$ denote the class of all continuous functions $\psi: \mathbb{R}_{++}^{2} \rightarrow \mathbb{R}_{++}$for which

- $\lim _{x_{1} \rightarrow 0} \psi\left(x_{1}, x_{2}\right)=\infty$ for all $x \in \mathbb{R}_{++}^{2} ;$

- $\lim _{x_{2} \rightarrow 0} \psi\left(x_{1}, x_{2}\right)=0$ for all $x \in \mathbb{R}_{++}^{2}$;

- $\psi(x) \geq \psi(y)$ for all $x, y \in \mathbb{R}_{++}^{2}$ for which $x_{1}<y_{1}$ and $x_{2}>y_{2}$.

For any $\psi \in \Psi$ and any $(E, c) \in \mathrm{BR}^{N}$ for which $N=N_{+}^{c}=\{1,2\}$ and $c \notin E$, let $\xi \in \operatorname{WP}(E)$ be defined such that $\psi(\xi)=\frac{c_{2}-\xi_{2}}{c_{1}-\xi_{1}}$. Note that $\xi$ exists and is uniquely defined.

For any $\psi \in \Psi$ for which $\psi\left(\frac{1}{2}, \frac{1}{2}\right)=1$, the bankruptcy rule $f_{1}^{\psi}: \mathrm{BR}^{N} \rightarrow \mathbb{R}_{+}^{N}$ assigns to any $(E, c) \in \mathrm{BR}^{N}$ the payoff allocation

$$
f_{1}^{\psi}(E, c)= \begin{cases}\xi & \text { if } N=N_{+}^{c}=\{1,2\}, E=\left\{x \in \mathbb{R}_{+}^{N} \mid x_{1}+x_{2} \leq 1\right\}, \text { and } c \notin E ; \\ \operatorname{Prop}(E, c) & \text { otherwise. }\end{cases}
$$

Note that $f_{1}^{\psi}=$ Prop if and only if $\psi(x)=\frac{x_{2}}{x_{1}}$ for all $x \in \mathbb{R}_{++}^{2}$.

For any $\psi \in \Psi$, the bankruptcy rule $f_{2}^{\psi}: \mathrm{BR}^{N} \rightarrow \mathbb{R}_{+}^{N}$ assigns to any $(E, c) \in \mathrm{BR}^{N}$ the payoff allocation

$$
f_{2}^{\psi}(E, c)= \begin{cases}\xi & \text { if } N=N_{+}^{c}=\{1,2\} \text { and } c \notin E \\ \operatorname{Prop}(E, c) & \text { otherwise. }\end{cases}
$$

Note that $f_{2}^{\psi}=$ Prop if and only if $\psi(x)=\frac{x_{2}}{x_{1}}$ for all $x \in \mathbb{R}_{++}^{2}$.

The truncated proportional rule satisfies relative symmetry and independence of unclaimed alternatives, but does not satisfy weak claims convexity. Any bankruptcy rule $f_{1}^{\psi} \neq$ Prop satisfies relative symmetry and claims linearity, but does not satisfy independence of unclaimed alternatives. Any bankruptcy rule $f_{2}^{\psi} \neq$ Prop satisfies independence of

\begin{tabular}{|c|c|c|c|c|}
\hline & Prop & TProp & $f_{1}^{\psi} \neq$ Prop & $f_{2}^{\psi} \neq$ Prop \\
\hline relative symmetry & $\checkmark$ & $\checkmark$ & $\checkmark$ & \\
\hline independence of unclaimed alternatives & & & & \\
\hline claims linearity & $\checkmark$ & & & $\checkmark$ \\
\hline weak claims linearity & $\checkmark$ & & $\checkmark$ & $\checkmark$ \\
\hline claims convexity & $\checkmark$ & & $\checkmark$ & $\checkmark$ \\
\hline weak claims convexity & $\checkmark$ & & $\checkmark$ & $\checkmark$ \\
\hline
\end{tabular}
unclaimed alternatives and claims linearity, but does not satisfy relative symmetry.

This means that relative symmetry and independence of unclaimed alternatives are independent of any claims axiom. In particular, the properties in Theorem 4.3 are independent. Moreover, the properties in the axiomatic characterization of the proportional rule remain independent if weak claims linearity in Theorem 4.3 is strengthened to claims linearity. 
The proportional rule is not the unique bankruptcy rule satisfying relative symmetry, independence of unclaimed alternatives, and claims convexity. The restricted proportional rule $\mathrm{RProp}: \mathrm{BR}^{N} \rightarrow \mathbb{R}_{+}^{N}$, which assigns to any $(E, c) \in \mathrm{BR}^{N}$ the payoff allocation

$$
\operatorname{RProp}(E, c)= \begin{cases}\operatorname{Prop}(E, c) & \text { if } c<u^{E} \\ \left(t c_{S}, 0_{N \backslash S}\right) & \text { otherwise }\end{cases}
$$

where $S=\left\{i \in N \mid \forall_{j \in N}: c_{j} u_{i}^{E} \leq c_{i} u_{j}^{E}\right\}$ and $t \in(0,1]$ is such that $\operatorname{RProp}(E, c) \in$ $\mathrm{WP}(E)$, also satisfies relative symmetry, independence of unclaimed alternatives, and claims convexity. However, if positive claimants are required to get positive awards, then these properties are only satisfied by the proportional rule.

Definition 4.2 (Positive Awards)

A bankruptcy rule $f: \mathrm{BR}^{N} \rightarrow \mathbb{R}_{+}^{N}$ satisfies positive awards if $f_{N_{+}^{c}}(E, c)>0_{N_{+}^{c}}$ for all $(E, c) \in \mathrm{BR}^{N}$.

\section{Theorem 4.4}

The proportional rule is the unique bankruptcy rule satisfying relative symmetry, independence of unclaimed alternatives, weak claims convexity, and positive awards.

Proof. The proportional rule satisfies relative symmetry. By Lemma 3.1. Lemma 4.1, Lemma A.1. Lemma A.5. and Lemma A.6. the proportional rule satisfies independence of unclaimed alternatives, weak claims convexity, and positive awards. Let $f: \mathrm{BR}^{N} \rightarrow \mathbb{R}_{+}^{N}$ be a bankruptcy rule satisfying relative symmetry, independence of unclaimed alternatives, weak claims convexity, and positive awards. Let $(E, c) \in \mathrm{BR}^{N}$. If $\left|N_{+}^{c}\right|=1$, then $f(E, c)=\left(u_{N_{+}^{c}}^{E}, 0_{N \backslash N_{+}^{c}}\right)=\operatorname{Prop}(E, c)$. Suppose that $\left|N_{+}^{c}\right| \geq 2$. Since $f$ satisfies positive awards, there exists an $x \in \mathbb{R}_{+}^{N}$ with $x=\theta c+(1-\theta) f(E, c)$ for some $\theta \in(0,1]$ such that $x<u^{E}$. Since $f$ satisfies relative symmetry and independence of unclaimed alternatives, Lemma 3.4 implies that $f(E, x)=\operatorname{Prop}(E, x)$. Since $f$ satisfies weak claims convexity, this implies that $f(E, c)=f(E, x)=\operatorname{Prop}(E, x)=\operatorname{Prop}(E, c)$.

The restricted proportional rule satisfies relative symmetry, independence of unclaimed alternatives, and claims convexity, but does not satisfy positive awards. The truncated proportional rule satisfies relative symmetry, independence of unclaimed alternatives, and positive awards, but does not satisfy weak claims convexity. The constrained relative equal awards rule satisfies relative symmetry, claims convexity, and positive awards, but does not satisfy independence of unclaimed alternatives. The constrained equal awards rule satisfies independence of unclaimed alternatives, claims convexity, and positive awards, but does not satisfy relative symmetry.

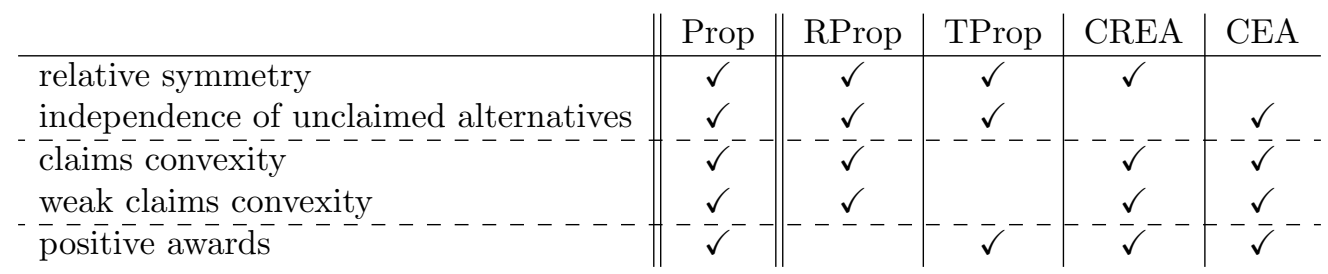

This means that the properties in Theorem 4.4 are independent. Moreover, the properties in the axiomatic characterization of the proportional rule remain independent if weak claims convexity in Theorem 4.4 is strengthened to claims convexity. 


\section{Concluding Remarks}

In this paper, we derived new axiomatic characterizations of the proportional rule, the truncated proportional rule, and the constrained relative equal awards rule for bankruptcy problems with nontransferable utility using axioms from bargaining theory. An overview of the corresponding properties, including the standard bankruptcy axioms relative symmetry and truncation invariance, the axioms concerning changes in the estate, the axioms concerning changes in the claims, and the weak technical requirements claims continuity and positive awards, is provided in the following table. The constrained equal awards rule is included for illustrative purposes.

\begin{tabular}{|c|c|c|c|c|}
\hline & Prop & TProp & CREA & CEA \\
\hline $\begin{array}{l}\text { relative symmetry } \\
\text { truncation invariance }\end{array}$ & $\checkmark$ & $\checkmark$ & $\checkmark$ & 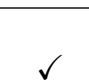 \\
\hline step-by-step negotiations & $\checkmark$ & & & \\
\hline estate monotonicity & $\checkmark$ & & & $\checkmark$ \\
\hline domination & $\checkmark$ & & & $\checkmark$ \\
\hline independence of irrelevant alternatives & $\checkmark$ & & & $\checkmark$ \\
\hline independence of undominating alternatives & $\checkmark$ & & & $\checkmark$ \\
\hline independence of unclaimed alternatives & $\checkmark$ & & & \\
\hline claims continuity & $\checkmark$ & & & $\bar{v}$ \\
\hline claims linearity & $\checkmark$ & & & \\
\hline weak claims linearity & $\checkmark$ & & $\checkmark$ & $\checkmark$ \\
\hline claims convexity & $\checkmark$ & & $\checkmark$ & $\checkmark$ \\
\hline 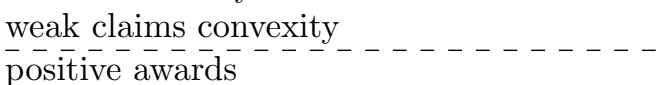 & & & & $-\checkmark$ \\
\hline
\end{tabular}

Alternatively, one could also interpret solutions for bargaining problems as new rules for bankruptcy problems, in line with the work of Dagan and Volij (1993) for bankruptcy problems with transferable utility. Future research allows to formalize this reverse approach in order to further connect bankruptcy problems with bargaining problems.

A bankruptcy rule based on the solution of Nash (1950) could maximize the product of the utility payoffs of all positive claimants over the truncated estate. On the domain of bankruptcy rules with convex estate, such a Nash bankruptcy rule bears some similarities with the constrained equal awards rule, since it satisfies truncation invariance, independence of irrelevant alternatives, and weak claims linearity, but does not satisfy relative symmetry.

The proportional rule for bankruptcy problems corresponds to a specific proportional solution for bargaining problems as studied by Kalai (1977) and Roth (1979).

Where the solution of Kalai and Smorodinsky (1975) let the utopia values of the rational payoff allocations determine an outcome direction, the solution of Kalai and Rosenthal (1978) let the utopia values of all payoff allocations within the feasible set determine an outcome direction for bargaining problems. For bankruptcy problems, this translates to the utopia values of the truncated estate and the utopia values of the estate, respectively. In this way, the solution of Kalai and Smorodinsky (1975) induces the truncated proportional rule and the solution of Kalai and Rosenthal (1978), when explicitly bounded by the claims, induces the constrained relative equal awards rule.

Other solutions for bargaining problems were introduced by Freimer and Yu (1976), which would prescribe the feasible payoff allocation with minimal distance to the vector of claims or the vector of utopia values in the context of bankruptcy problems. A similar solution is also studied by Mariotti and Villar (2005). 


\section{References}

Chun, Y. and W. Thomson (1990). Nash solution and uncertain disagreement points. Games and Economic Behavior, 2(3), 213-223.

Chun, Y. and W. Thomson (1992). Bargaining problems with claims. Mathematical Social Sciences, 24(1), 19-33.

Dagan, N. and O. Volij (1993). The bankruptcy problem: a cooperative bargaining approach. Mathematical Social Sciences, 26(3), 287-297.

Dietzenbacher, B. (2018). Bankruptcy games with nontransferable utility. Mathematical Social Sciences, 92, 16-21.

Dietzenbacher, B., P. Borm, and A. Estévez-Fernández (2017). NTU-bankruptcy problems: consistency and the relative adjustment principle. CentER Discussion Paper, 2017044.

Dietzenbacher, B., A. Estévez-Fernández, P. Borm, and R. Hendrickx (2016). Proportionality, equality, and duality in bankruptcy problems with nontransferable utility. CentER Discussion Paper, 2016-026.

Estévez-Fernández, A., P. Borm, and M. Fiestras-Janeiro (2014). Nontransferable utility bankruptcy games. Tinbergen Institute Discussion Paper, TI 2014-30/II.

Freimer, M. and P. Yu (1976). Some new results on compromise solutions for group decision problems. Management Science, 22(6), 688-693.

Herrero, C. (1997). Endogenous reference points and the adjusted proportional solution for bargaining problems with claims. Social Choice and Welfare, 15(1), 113-119.

Kalai, E. (1977). Proportional solutions to bargaining situations: interpersonal utility comparisons. Econometrica, 45(7), 1623-1630.

Kalai, E. and R. Rosenthal (1978). Arbitration of two-party disputes under ignorance. International Journal of Game Theory, 7(2), 65-72.

Kalai, E. and M. Smorodinsky (1975). Other solutions to Nash's bargaining problem. Econometrica, 43(3), 513-518.

Livne, Z. (1988). The bargaining problem with an uncertain conflict outcome. Mathematical Social Sciences, 15(3), 287-302.

Mariotti, M. and A. Villar (2005). The Nash rationing problem. International Journal of Game Theory, 33(3), 367-377.

Nash, J. (1950). The bargaining problem. Econometrica, 18(2), 155-162.

O'Neill, B. (1982). A problem of rights arbitration from the Talmud. Mathematical Social Sciences, 2(4), 345-371.

Orshan, G., F. Valenciano, and J. Zarzuelo (2003). The bilateral consistent prekernel, the core, and NTU bankruptcy problems. Mathematics of Operations Research, 28(2), $268-282$.

Peters, H. (2010). Characterizations of bargaining solutions by properties of their status quo sets. In: A. van Deemen and A. Rusinowska (Eds.), Collective Decision Making, pp. 231-247. Berlin Heidelberg: Springer.

Peters, H. and E. van Damme (1991). Characterizing the Nash and Raiffa bargaining solutions by disagreement point axioms. Mathematics of Operations Research, 16(3), $447-461$. 
Raiffa, H. (1953). Arbitration schemes for generalized two-person games. In: H. Kuhn and A. Tucker (Eds.), Contributions to the Theory of Games II, pp. 361-387. Princeton: Princeton University Press.

Roth, A. (1977). Independence of irrelevant alternatives, and solutions to Nash's bargaining problem. Journal of Economic Theory, 16(2), 247-251.

Roth, A. (1979). Proportional solutions to the bargaining problem. Econometrica, 47(3), $775-778$.

Thomson, W. and R. Myerson (1980). Monotonicity and independence axioms. International Journal of Game Theory, 9(1), 37-49.

\section{Appendix}

\section{Lemma 3.1}

Proof. (i) Assume that $f$ satisfies step-by-step negotiations. Let $(E, c),\left(E^{\prime}, c\right) \in \mathrm{BR}^{N}$ be such that $E^{\prime} \subseteq E$. Then $f(E, c)=f\left(E^{\prime}, c\right)+f\left(\left(E-\left\{f\left(E^{\prime}, c\right)\right\}\right)_{+}, c-f\left(E^{\prime}, c\right)\right) \geq f\left(E^{\prime}, c\right)$. Hence, $f$ satisfies estate monotonicity.

(ii) Assume that $f$ satisfies estate monotonicity. Let $(E, c),\left(E^{\prime}, c\right) \in \mathrm{BR}^{N}$. Suppose that $f(E, c) \in E^{\prime}$. Then $f(E, c) \in \mathrm{WP}\left(E \cap E^{\prime}\right), f\left(E \cap E^{\prime}, c\right) \leq f(E, c)$, and $f\left(E \cap E^{\prime}, c\right) \leq f\left(E^{\prime}, c\right)$. Since $E$ is nonleveled, this implies that $f(E, c)=f\left(E \cap E^{\prime}, c\right) \leq f\left(E^{\prime}, c\right)$.

Now suppose that $f(E, c) \notin E^{\prime}$. Since $E$ is comprehensive, this means that $f(E, c) \in$ $\mathrm{WP}\left(E \cup E^{\prime}\right), f(E, c) \leq f\left(E \cup E^{\prime}, c\right)$, and $f\left(E^{\prime}, c\right) \leq f\left(E \cup E^{\prime}, c\right)$. Since $E$ is nonleveled, this implies that $f(E, c)=f\left(E \cup E^{\prime}, c\right) \geq f\left(E^{\prime}, c\right)$. Hence, $f$ satisfies domination.

(iii) Assume that $f$ satisfies domination. Let $(E, c),\left(E^{\prime}, c\right) \in \mathrm{BR}^{N}$ be such that $E^{\prime} \subseteq E$. Then $f(E, c) \leq f\left(E^{\prime}, c\right)$ or $f(E, c) \geq f\left(E^{\prime}, c\right)$. Since $E$ is nonleveled, this implies that $f\left(E^{\prime}, c\right) \leq f(E, c)$. Hence, $f$ satisfies estate monotonicity.

(iv) Assume that $f$ satisfies estate monotonicity. Let $(E, c),\left(E^{\prime}, c\right) \in \mathrm{BR}^{N}$ be such that $E^{\prime} \subseteq E$ and $f(E, c) \in \mathrm{WP}\left(E^{\prime}\right)$. Then $f(E, c) \geq f\left(E^{\prime}, c\right)$. Since $E$ is nonleveled, this implies that $f(E, c)=f\left(E^{\prime}, c\right)$. Hence, $f$ satisfies independence of irrelevant alternatives.

(v) Assume that $f$ satisfies estate monotonicity. Let $(E, c),\left(E^{\prime}, c\right) \in \mathrm{BR}^{N}$ be such that $E^{\prime} \subseteq E$ and $f\left(E^{\prime}, c\right) \in \mathrm{WP}(E)$. Then $f(E, c) \geq f\left(E^{\prime}, c\right)$. Since $E$ is nonleveled, this implies that $f(E, c)=f\left(E^{\prime}, c\right)$. Hence, $f$ satisfies independence of undominating alternatives.

(vi) Assume that $f$ satisfies independence of irrelevant alternatives. Let $(E, c),\left(E^{\prime}, c\right) \in$ $\mathrm{BR}^{N}$ be such that $\hat{E}_{c}=\hat{E}_{c}^{\prime}$. Then $f(E, c), f\left(E^{\prime}, c\right) \in \operatorname{WP}\left(E \cap E^{\prime}\right)$. This implies that $f(E, c)=f\left(E \cap E^{\prime}, c\right)=f\left(E^{\prime}, c\right)$. Hence, $f$ satisfies independence of unclaimed alternatives.

(vii) Assume that $f$ satisfies independence of undominating alternatives. Let $(E, c) \in$ $\mathrm{BR}^{N}$ and $\left(E^{\prime}, c\right) \in \mathrm{BR}^{N}$ be such that $\hat{E}_{c}=\hat{E}_{c}^{\prime}$. Then $f(E, c), f\left(E^{\prime}, c\right) \in \operatorname{WP}\left(E \cup E^{\prime}\right)$. This implies that $f(E, c)=f\left(E \cup E^{\prime}, c\right)=f\left(E^{\prime}, c\right)$. Hence, $f$ satisfies independence of unclaimed alternatives. 


\section{Lemma A.1}

The proportional rule satisfies step-by-step negotiations.

Proof. Let $(E, c),\left(E^{\prime}, c\right) \in \mathrm{BR}^{N}$ be such that $E^{\prime} \subseteq E$. Then $\operatorname{Prop}(E, c)=\lambda^{E, c} c$ and

$$
\begin{aligned}
& \operatorname{Prop}\left(E^{\prime}, c\right)+\operatorname{Prop}\left(\left(E-\left\{\operatorname{Prop}\left(E^{\prime}, c\right)\right\}\right)_{+}, c-\operatorname{Prop}\left(E^{\prime}, c\right)\right) \\
= & \lambda^{E^{\prime}, c} c+\operatorname{Prop}\left(\left(E-\left\{\lambda^{E^{\prime}, c} c\right\}\right)_{+}, c-\lambda^{E^{\prime}, c} c\right) \\
= & \lambda^{E^{\prime}, c} c+\lambda^{\left(E-\left\{\lambda^{E^{\prime}, c} c\right\}\right)_{+},\left(1-\lambda^{E^{\prime}, c}\right) c}\left(1-\lambda^{E^{\prime}, c}\right) c \\
= & \left(\lambda^{E^{\prime}, c}+\lambda^{\left(E-\left\{\lambda^{E^{\prime}, c} c\right\}\right)_{+},\left(1-\lambda^{E^{\prime}, c}\right) c}\left(1-\lambda^{E^{\prime}, c}\right)\right) c .
\end{aligned}
$$

Moreover, $\operatorname{Prop}\left(E^{\prime}, c\right)+\operatorname{Prop}\left(\left(E-\left\{\operatorname{Prop}\left(E^{\prime}, c\right)\right\}\right)_{+}, c-\operatorname{Prop}\left(E^{\prime}, c\right)\right) \in \mathrm{WP}(E)$. Since $E$ is nonleveled, this implies that $\operatorname{Prop}\left(E^{\prime}, c\right)+\operatorname{Prop}\left(\left(E-\left\{\operatorname{Prop}\left(E^{\prime}, c\right)\right\}\right)_{+}, c-\operatorname{Prop}\left(E^{\prime}, c\right)\right)=$ $\operatorname{Prop}(E, c)$. Hence, the proportional rule satisfies step-by-step negotiations.

\section{Lemma A.2}

The truncated proportional rule satisfies independence of unclaimed alternatives.

Proof. Let $(E, c),\left(E^{\prime}, c\right) \in \mathrm{BR}^{N}$ be such that $\hat{E}_{c}=\hat{E}_{c}^{\prime}$. Then $\hat{E}_{\hat{c}^{E}}=\hat{E}_{c}=\hat{E}_{c}^{\prime}=\hat{E}_{\hat{c}^{E^{\prime}}}^{\prime}$ and $\hat{c}^{E}=u^{\hat{E}_{c}}=u^{\hat{E}_{c}^{\prime}}=\hat{c}^{E^{\prime}}$. By Lemma 3.1 and Lemma A.1 the proportional rule satisfies independence of unclaimed alternatives. Then

$$
\operatorname{TProp}(E, c)=\operatorname{Prop}\left(E, \hat{c}^{E}\right)=\operatorname{Prop}\left(E^{\prime}, \hat{c}^{E^{\prime}}\right)=\operatorname{TProp}\left(E^{\prime}, c\right) .
$$

Hence, the truncated proportional rule satisfies independence of unclaimed alternatives.

\section{Lemma A.3}

The truncated proportional rule satisfies claims continuity.

Proof. Let $(E, c) \in \mathrm{BR}^{N}$. Then $\lim _{x \rightarrow c} \hat{x}^{E}=\hat{c}^{E}, \lim _{x \rightarrow c} \lambda^{E, \hat{x}^{E}}=\lambda^{E, \hat{c}^{E}}$, and

$$
\begin{aligned}
\lim _{x \rightarrow c} \operatorname{TProp}(E, x) & =\lim _{x \rightarrow c} \operatorname{Prop}\left(E, \hat{x}^{E}\right)=\lim _{x \rightarrow c} \lambda^{E, \hat{x}^{E}} \hat{x}^{E}=\lim _{x \rightarrow c} \lambda^{E, \hat{x}^{E}} \lim _{x \rightarrow c} \hat{x}^{E} \\
& =\lambda^{E, \hat{c}^{E}} \hat{c}^{E} \\
& =\operatorname{Prop}\left(E, \hat{c}^{E}\right)=\operatorname{TProp}(E, c) .
\end{aligned}
$$

Hence, the truncated proportional rule satisfies claims continuity.

\section{Lemma A.4}

The constrained relative equal awards rule satisfies weak claims linearity.

Proof. Let $(E, c) \in \mathrm{BR}^{N}$ and let $\theta \in \mathbb{R}_{+}$. Suppose that $\alpha^{E, \theta c+(1-\theta) \operatorname{CREA}(E, c)} \geq \alpha^{E, c}$. For all $i \in N$,

$$
\begin{aligned}
& \operatorname{CREA}_{i}(E, \theta c+(1-\theta) \operatorname{CREA}(E, c)) \\
= & \min \left\{\theta c_{i}+(1-\theta) \operatorname{CREA}_{i}(E, c), \alpha^{E, \theta c+(1-\theta) \operatorname{CREA}(E, c)} u_{i}^{E}\right\} \\
= & \min \left\{\mathrm{CREA}_{i}(E, c)+\theta\left(c_{i}-\operatorname{CREA}_{i}(E, c)\right), \alpha^{E, \theta c+(1-\theta) \operatorname{CREA}(E, c)} u_{i}^{E}\right\} \\
\geq & \min \left\{\mathrm{CREA}_{i}(E, c), \alpha^{E, c} u_{i}^{E}\right\} \\
= & \operatorname{CREA}_{i}(E, c) .
\end{aligned}
$$

Since $E$ is nonleveled, this implies that $\operatorname{CREA}(E, c)=\operatorname{CREA}(E, \theta c+(1-\theta) \operatorname{CREA}(E, c))$. 
Now, suppose that $\alpha^{E, \theta c+(1-\theta) \operatorname{CREA}(E, c)} \leq \alpha^{E, c}$. For all $i \in N$,

$$
\begin{aligned}
& \operatorname{CREA}_{i}(E, \theta c+(1-\theta) \operatorname{CREA}(E, c)) \\
= & \min \left\{\theta c_{i}+(1-\theta) \operatorname{CREA}_{i}(E, c), \alpha^{E, \theta c+(1-\theta) \operatorname{CREA}(E, c)} u_{i}^{E}\right\} \\
= & \min \left\{\mathrm{CREA}_{i}(E, c)+\theta\left(c_{i}-\mathrm{CREA}_{i}(E, c)\right), \alpha^{E, \theta c+(1-\theta) \operatorname{CREA}(E, c)} u_{i}^{E}\right\} \\
\leq & \min \left\{\mathrm{CREA}_{i}(E, c)+\theta\left(c_{i}-\mathrm{CREA}_{i}(E, c)\right), \alpha^{E, c} u_{i}^{E}\right\} \\
= & \operatorname{CREA}_{i}(E, c) .
\end{aligned}
$$

Since $E$ is nonleveled, this implies that $\operatorname{CREA}(E, c)=\operatorname{CREA}(E, \theta c+(1-\theta) \operatorname{CREA}(E, c))$. Hence, the constrained relative equal awards rule satisfies weak claims linearity.

\section{Lemma A.5}

The proportional rule satisfies claims linearity.

Proof. Let $(E, c),\left(E, c^{\prime}\right) \in \mathrm{BR}^{N}$ be such that $\operatorname{Prop}(E, c)=\operatorname{Prop}\left(E, c^{\prime}\right)$, and let $\theta \in \mathbb{R}$ be such that $\left(E, \theta c+(1-\theta) c^{\prime}\right) \in \mathrm{BR}^{N}$. Then $\lambda^{E, c} c=\lambda^{E, c^{\prime}} c^{\prime}$ and

$\operatorname{Prop}\left(E, \theta c+(1-\theta) c^{\prime}\right)=\lambda^{E, \theta c+(1-\theta) c^{\prime}}\left(\theta c+(1-\theta) c^{\prime}\right)=\lambda^{E, \theta c+(1-\theta) c^{\prime}}\left(\theta+(1-\theta) \frac{\lambda^{E, c}}{\lambda^{E, c^{\prime}}}\right) c$.

Since $E$ is nonleveled, this implies that $\operatorname{Prop}(E, c)=\operatorname{Prop}\left(E, \theta c+(1-\theta) c^{\prime}\right)$. Hence, the proportional rule satisfies claims linearity.

\section{Lemma A.6}

The proportional rule satisfies positive awards.

Proof. Let $(E, c) \in \mathrm{BR}^{N}$ and let $i \in N_{+}^{c}$. Then $\operatorname{Prop}_{i}(E, c)=\lambda^{E, c} c_{i}>0$. Hence, the proportional rule satisfies positive awards. 